The Geneva Papers on Risk and Insurance, 17 (No. 63, April 1992), 244-256

\title{
The Role of the International Maritime Organization (IMO) in the Management of Maritime Risks
}

\author{
by Agustin Blanco-Bazán *
}

\section{Introduction}

1.1. IMO is the only spccialized agency of the Unitcd Nations wholly dedicatcd to maritimc affairs. Its activities, which were initiatcd in 1959, have been focuscd on the elaboration and adoption of conventions, protocols and recommendations to be implemented in the field of maritime safety, efficiency of navigation and the prevention of marine pollution. IMO has also developed treaty instruments with the purpose of unifying international law in questions of liability and compensation for damage resulting from ships' activitics and, in particular, from vessels' source pollution. IMO activities have resulted in the elaboration of 35 international treaty instruments (conventions and protocols) and well over 600 codes and recommendations.

1.2. The continuous elaboration of international provisions undertaken at IMO should be primarily understood as an answer to the compelling nceds arising out of the extremcly fast and changing patterns of international navigation which have taken placc during the last four decades.

1.3. The existence and activities of IMO are justified by the consensus of its 135 member countrics that these risks to safety of navigation and to the marine environment should be controlled and reduced with the help of international rcgulations. These rcgulations are mandatory if contained in conventions and protocols, and non-mandatory in the case of recommendations.

1.4. The first part of this paper analyzes technical and lcgal aspects involved in the management of maritime risks related to the scope of activities of IMO, namely, the safety of navigation and prevention of pollution from ships. These activities will be considered in as far

\footnotetext{
* Senior Legal Officer at the International Maritime Organization (IMO).

The views in this paper are exclusively those of the author and do not necessarily represent the views or position of IMO.
} 
as they decisively influence the management of maritime risks: the achievement of highest standards of safety of navigation and prevention of pollution results in the avoidance of maritime accidents and consequently the minimization of losses.

1.5. A second part of the paper will be devoted to the work of $1 \mathrm{MO}$ in pursuance of adequate compensation for those who have suffered damage as a consequence of marine accidents in general and of marine pollution in particular. In this case, IMO activities are closely related to third party liability marine insurance: the role of the insurer is to pay amounts of compensation for accidents resulting from the activities of the insured shipowner; the limits to these amounts are established in international conventions adopted at IMO conferences.

\section{Safety of navigation and prevention of pollution of the seas}

2.1. For a long time the scope of marine insurance has been mainly concerned with safety risks; these risks exclusively refer to safety of navigation, and the corresponding risk prevention activities are governed by regulations which purport to ensure that the possibility of accidents affecting the insurable property are minimal. Hence the requirements of age, fittings, equipment and crew skills which should be borne in mind when underwriting a policy.

2.2. Sea pollution involves risks of a radically different kind. Preventive measures are here designed to avoid a kind of damage of a dimension ignored a few decades ago. Traditionally the sea has been the very residual place in the planet to dispose of any kind of wastes. It would have then been strange if, as it happens now, mandatory equipment or fittings had been imposed not to protect the property or persons on board but to prevent the pollution of the marine environment. Imagine the situation of a shipowner having to invest not only in radar or life saving equipment but also in devices like an oil discharge monitoring and control system. In this latter case risk management is not associated with the direct interests of the shipowner but with a different kind of interest, namely those related to the protection of tourism and fisheries, as well as the prevention of an ecological system of vital importance for the survival of mankind. Nobody would have been accused of polluting the sea fifty years ago. Nowadays such pollution is prevented by international treaty instruments, national laws and. in most of the cases. severe penalties imposed on the polluters by coastal and port States.

2.3. The different approach to safety of navigation and prevention of pollution has resulted in the very distinctive features shown by the international regulations governing risk mandgement in each of these cases. The basic rules concerning safety of navigation have been accepted for a long time by the international community as a source of legal obligations imposed upon flag, coastal and port States as well as on shipowners. In this respect, the provisions on safe navigation included in the Convention of the United Nations on the Law of the Sea (UNCLOS) frequently do no more than make this general acceptance explicit. But what about the prevention of pollution, in view of the fact that, as it has been previously stated, the sea has been considered for such a long time as a generally accepted place to dispose of any sort of wastes? It is obvious that we cannot say here that the whole Part XII of UNCLOS (Protection and preservation of the marine environment) is enshrining long accepted principles of international law. This dilemma can be solved by explaining that only 
recently sea pollution has become the source of widespread catastrophic damage due to the appearance of oil and gas carriers, and the transportation by sea of goods of an extremely dangerous entity. Thus, the enactment of regulations to protect the marine environment is justified in accordance with the most obvious and ancient principles upon which any law national or international - is necesse rily based: whenever there is a legitimate interest to be protected, the enactment of appropriatc legislation is a sine-qua-non to ensure peace among nations and individuals.

2.4. Law making techniques in respect of safety of navigation and prevention of pollution are closely related to the interests to be protected: in matters of safety, the initial private nature of the property interests involved in a maritime adventure has been transformed by the perception that there is also a public interest to be taken into account in the protection of crews and passengers, the avoidance of accidents likely to obstruct navigation and the need to ensure the safe transportation of goods which are of vital importance for the economy of any country. Preventive measures against pollution involve considerations of a more public nature, for the damage likely to be caused is expansive, in too many cases catastrophic, and normally inflicted on persons other than the polluter. Safety of navigation and prevention of pollution are closely related to each other in certain cases such as the extremely demanding safety measures required to avoid fire and explosion in a supertanker, which if sunk or stranded, would cause widespread pollution.

2.5. Many countries have produced their own legislation in safety navigation and prevention of pollution for the ships registered in their ports and flying their flags. Equally, the international insurance market and the classification societies have decisively contributed to the achievement of ever higher standards of safety. However the most important development during the last forty years has been the adoption of international conventions providing in extreme detail for mandatory provisions regulating safety risks. Equally, a comprehensive convention has been adopted to prevent pollution from ships. The International Maritime Organization ( $1 \mathrm{MO}$ ) has played a leading role in the adoption of these treaty instruments of universal value.

2.6. The backbone of the IMO safety conventions is the International Convention for the Safety of Life at Sea ("SOLAS 74"). Other main IMO safety conventions are the Protocol of 1978 relating to the International Convention for the Safety of Life at Sea, 1974 ("SOLAS PROTOCOL 1978"), the International Convention on Load Lines, 1966 ("LL 66"), the Convention on the International Regulations for Preventing Collisions at Sca, 1972 ("COL REG 72"), and the International Convention on Standards of Training, Certification and Watchkeeping for Seafarers, 1978 ("STCW 78").

2.7. The International Convention for the Prevention of Pollution from Ships, 1973, as modified by the Protocol 1978, normally referred to as "MARPOL 73/78" is the first international treaty regulating the prevention of marine pollution from vesscls' source.

\subsection{A list of treaty instruments adopted at $1 \mathrm{MO}$ is attached as annex to this paper.}

2.9. The very precise technical provisions contained in these conventions regulate the performance of risk-management measures the aim of which is to prevent incidents likely to damage goods and lives at sea and to pollute the marine environment. In this regard the implementation of $1 \mathrm{MO}$ Conventions is of the utmost importance for the insurance industry: preventive measures are costly, for they normally involve important expenditure by 
shipowners in terms of equipment, maintenance, manning and training, as well as the need of periodical inspections by specialized bodies such as classification societies. However statistics show that these measures have successfully reduced the occurrence of insurance losses. Moreover, since most of the commercial fleets fly the flag of States Party to IMO conventions, the conventions' provisions are universally implemented. As a result, the risks involved are managed, worldwide in an homogeneous way. This feature is the result of a difficult evolution characterized by the need to impose upon shipowners ever more stringent technical regulations to comply with.

\section{Main features of maritime risks regulated by IMO conventions}

3.1. 1MO's task of adopting the highest practicable standards in marine safety and the prevention of marine pollution from ships suggests the need for ensuring the implementation of these standards through adequate regulations to which shipowners and ship-operators should adhere. These standards, which are intended to be applied universally, mean a response to the ever increasing dimension of risks posed by modern navigation. It is a matter of fact that the more modern technology advances in any branch of industry (be this shipping or any other) the more precise and articulated the legal provisions must be to ensure an adequate risk management. Technology is a phenomenon which, to be adequately controlled, requires an increasing number of legal provisions of a very precise kind. This phenomenon is the source of relevant considerations and dilemmas for those interested in the philosophical and sociological aspects of law: in order to control the ever increasing risks resulting from the development of new technologies, governments and international organizations must elaborate increasing numbers of binding provisions to be either passed into the domestic law or included in international conventions. This proliferation of legal requirements should not result in excesses likely to affect in a negative way economic and commercial activities of paramount importance. It frequently happens that the need for new regulations is established as a consequence of accidents which provoke a reaction in the public opinion of the countries affected. This reaction presses the governments concerned to take measures in order to ensure that accidents will not be repeated. It is within this framework that governments resort to IMO in order to introduce higher and more sophisticated technical standards into IMO conventions. The disaster of the "Herald of the Free Enterprise" and the introduction of amendments to SOLAS at the proposal of the United Kingdom is one of the latest examples of the above.

3.2. As a result of the extremely fast technological development experienced by the shipping industry, vessels engaged in international commercial navigation are subject to continuous improvement in design, construction and equipment. These improvements should help to increase their commercial viability while ensuring that the likelihood of accidents is reduced to a minimum. The different kinds of risks involved in the carriage of a continuously increasing variety of goods has led to new types of vessels. They must be appropriately designed and fully equipped to the characteristics of the cargo they are carrying. The carriage of cargoes in bulk (such as coal or grain) requires ships designed solely for this purpose in order to prevent improper weight distribution likely to result in structural damage or improper stability during voyage. Dangerous goods, such as the ones produced by the oil, chemical and nuclear industries require the greatest possible care in their handling and carriage. Similar measures of extreme precaution must be adopted in respect of containers. The modern roll-on and roll-off (ro-ro) ships have posed a continuous challenge to those involved in the achievement of highest safety standards. 
3.3. All these circumstances have resulted in a dramatic change in the features of marine insurable risks during the last thirty years. These changes can be described by simply pointing out that although the possibility of accidents has been reduced by the continuous innovations in design and equipment, the characteristic of the risks involved are such, that if an accident occurs, the losses can very frequently be of a catastrophic kind. Technological advances normally mean accumulation and incrementation of the insurable risks and consequently call for a most sophisticated risk management. The underwriter' simply cannot take the chance of resorting to the financial game of insuring more ships in order to obtain a wider risk spread at the expense of disregarding safety measures: one total loss could have a catastrophic effect in its portfolio.

3.4. The preceding comments explain the need to control maritime risks by producing international regulations of a very precise kind to be applied worldwide. Maritime Administrations, shipowners and their insurers must know exactly how a gas carrier or a super-tanker should be constructed and which equipment on board should be used to prevent fire, explosion or wrecking, loss of the cargo and consequent pollution of the sea and damage to the marine environment. The risks involved in those examples are more sophisticated than those attached to the navigation of general cargo vessels half a century ago. The increased sophistication of the risks applies also to seafarers, who must now undergo special training to be in charge of vessels of different kinds which demand different safety requirements.

3.5. For this reason insurers should be more stringent than ever in demanding an adequate risk management through appropriate safety measures. Although the requirements set out by the classification societies are normally considered as being sufficient to satisfy minimal safety standards, the increasing magnitude of maritime risks has led to the active involvement of governments and international bodies in the achievement of compulsory safety regulations. The main IMO conventions represent the highest point of this achievement.

\section{Safety of navigation: inspections, surveys and certificates issued in compliance with IMO conventions. Role of the classification societies.}

4.1. Traditionally, the role of establishing safety standards and rules for design, construction and equipment of vessels has been assumed by Classification Societies. After surveying the ships, the societies issue a certificate attesting compliance with the above-mentioned rules and standards. Those certificates are of vital importance for the shipowner and shipoperator, as well as for the marine insurers for they define the seaworthiness of the ship. Without the appropriate certificate it is practically impossible for commercial vessels to engage themselves in international navigation. Upon arrival, most ports require their ships' master to show these certificates, which are considered as confimation that the ship complies with safety regulations. The granting of an insurance cover depends on the result of the surveys carried forward and the information contained in the certificates defining the type, size, age, class and fitness of the ship.

4.2. For the countries which have accepted the main IMO safety conventions, surveys and inspections of the ships flying their flag become compulsory. SOLAS 74, the SOLAS Protocol 78 and the Load Lines Convention of 1966 also provide for the issuance of certificates attesting compliance with the Convention requirements. The Maritime Administration of a State Party to a Convention must therefore ensure that surveys and inspections are performed and the certificates prescribed by the Convention properly issued. 
4.3. Nevertheless, the conventions expressly entitle the Maritime Administrations to delegate the tasks of surveys, inspections and issuance or certification upon other reliable institutions among which classification societies can be accounted. In this case the classification society could also be authorized to issue convention certificates attesting compliance with safety standards, and the Administration would endorse them.

4.4. It should be pointed out that whatever the method chosen by the Government (either to effect its own surveys and inspections or to delegate this power to classification societies) the Maritime Administration of the flag State assumes full responsibility for the certificate.

4.5. From the comments expressed above, it can be noticed that ships engaged in international commercial navigation must produce, on their arrival in most foreign ports the certificates regulated by the main IMO conventions, or if this State is not Party to such conventions, at least a certificate issued by a Classification Society. However, shipowners normally agree that it is more convenient to produce the Conventions' certificates before the authorities of the port State. The reason of this convenience is that if the port State is also Party to the Conventions, it must accept the conventions certificates on board foreign vessels as if they had been issued by itself. The Administration of the port State must verify that there is on board a valid certificate, and not proceed to inspect the ship unless there are clear grounds for believing that the condition of the ship or its equipment does not correspond with the particulars shown in the convention certificates. In the case of non-convention certificates issued by Classification Societies to ships flying the flag of a State not Party to a certain convention, this limitation does not exist. The Port State can accept the certificate issued by Classification Societies but it has discretional power to inspect the ship without any restriction. For this reason, ships carrying convention certificates are normally subjected to less delays than vessels carrying certificates which, although issued by a reliable classification society, are not convention certificates because their flag State is not Party to SOLAS 74, Protocol SOLAS or LL 66.

4.6. Among the institutions enjoying consultative status at IMO is the International Association of Classification Societies (IACS) as an institution enjoying consultative status at IMO. Other international bodies enjoying consultative status at IMO in order to co-operate in the task of helping the continuous improvement of safety standards are:

- The International Chamber of Shipping (ICS),

- The International Association of Independent Tanker Owners (INTERTANKO),

- The International Association of Lighthouse Authorities (IALA),

- The International Hydrographic Organization (IHO),

- The International Life Boat Federation.

4.7. The international bodies directly representing the interest of the insurance industry which also enjoy consultative status at IMO are the following:

- International Union of Marine Insurance (IUMI),

- International Association of Producers of Insurance and Reinsurance,

- International Groups of P \& I Clubs.

4.8. Most of the insurance maritime losses are due to non-compliance with safety measures prescribed in the IMO conventions. For this reason, it is of vital importance that any loss prevention activity is based on the full acceptance of the following underwriting policy: 
premiums should not be cstablished after a financial calculation on how much more would the cost of the insurance be when a ship is not in good condition. Sub-standard ships should not obtain insurance cover and should not navigate for they represent a great danger to persons and goods. The role of IMO and other international bodies in the prevention of losses can only be successful if insurers, classification societies, and any other institution directly or indirectly involved in risk management agrec on the truth of this basic principle.

\section{IMOS's activities in the prevention of marine pollution from ships}

5.1. During the last thirty years, the pollution of the world's oceans has become a matter of increasing intcrnational concern. Most of it comes from land-based sources and includes the by-products of industry, run-offs from agricultural pesticides and herbicides and effluents discharged from urban areas.

5.2. Nevertheless, a very significant amount of pollution is caused by shipping. The substances involved vary cnormously in the quantitics transported and their potential harm to the marine environment.

5.3. In tonnage terms, the most important pollutant resulting from shipping opcrations is oil, and the best known cause of oil pollution is tanker accidents such as the wrecks of the Torrey Canyon (1967) and the Amoco Cádiz (1978). Other oil pollution incidents occur during terminal operations, when oil is being loaded or discharged. However, a much greater quantity of oil enters the sea as a consequence of normal tanker operations, usually associated with the cleaning of cargo residues (clingage) which takes place when the ship is returning from the port of discharge to take another cargo of oil. The amount of clingage normally amounts to about 0.4 per cent of cargo carrying capacity - about 800 tons on a $200,000 \mathrm{dwt}$ crude oil carrier. Other causes of oil pollution include dry-docking, bilge and fuel oil and non-tanker accidents.

5.4. The marine environment can also be seriously damaged by other noxious substances and dangerous goods being carried by sea. Garbage and sewage from ships, which have traditionally been dumped into the sea as a matter of course can be also a source of pollution likely to affect the marine cnvironment.

5.5. IMO's activities have led to the adoption of the first ever comprehensive anti-pollution Convention, the International Convention for the Prevention of Pollution from Ships, as modified by the Protocol of 1978 relating thereto. The Convention, which is commonly known as "MARPOL 73/78" contains provisions aimed at prevention of pollution of the sea by oil discharged from ships; bulk liquid noxious substances other than oil discharged from ships (excluding the disposal of shore-generated wastes into the sea); noxious substances carried in packages or containers; shipboard scwage and ships gencratcd garbage. It also rcgulates the control of pollution through improved design, construction and cquipment of tankers carrying oil and ships transporting other noxious substances in bulk. These requirements arc regulated through five tcchnical annexes to the Convention, which also regulatc the issuance of an International Certificate (IOPC) attcsting compliance with the convention requirements on construction and equipment on board. It equally provides for the availability of reception facilities for ballast wastes in ports and the issuing of an Oil Record Book, in respect of cvery ship, recording the operations of loading and unloading, transfer of oil cargo during voyage, ballasting and clcaning of cargo tanks, discharge of dirty ballast, ctc. 
5.6. As in the case of safety conventions mentioned above, the fulfilment of the requirements contained in MARPOL 73/78, must be checked through by effecting the corresponding surveys and inspections as in the case of SOLAS 74, SOLAS Protocol 78 and Load Lines 66. The Maritime Administration can delegate the performance of these activities to specialized institutions and classification societies. The International Oil Pollution Certificate has a legal value similar to the Certificate regulated by the safety conventions.

\section{The role of IMO in the assessment of shipowners' liability for maritime claims}

6.1. All the IMO conventions we have briefly referred to so far are of a preventive kind: the regulations and standards they establish tend to prevent any incident likely to affect safety of navigation or to pollute the marine environment.

6.2. However IMO's activities are not restricted to this preventive scope. They also extend to the question of how to provide an adequate compensation for the victims of any incident involving the shipowners liability.

6.3. It is in this point that IMO activities become closely connected with the insurance protection granted to the shipowners to cover its liability against a Third Party. Traditionally, the shipowner could limit his liability in respect of maritime claims to the value of the ship plus its freight. However, this system gave an unfair advantage to the owner of the old or badly maintained vessels as compared with new or well-maintained ones. The owner would have to pay less in the first case, for the value of the ship considered to establish the limit of his liability would be less.

6.4. For this reason, the concept of limitation of liability of the shipowner was progressively modified in such a way that the true hull value of the ship was replaced by a deemed value consisting in a certain amount of money per ton. This last one should be calculated on the basis of the average market value of a ship of a size similar to the one in respect of which the claim was launched.

6.5. The Torrey Canyon incident occurred in 1967 clearly showed that, at least in the case of oil pollution, the shipowner's liability could not be related anymore to any real or notional concept of hull and cargo values. The traditional concept of shipowner's liability had been exposed as grossly inadequate to protect and compensate those affected by oil pollution damage: whatever the systein to calculate the value of the hull and the freight, the resulting amount would be insufficient to provide an equitable compensation.

6.6. As a response to this problem, an international conference convened by IMO in 1969 adopted the International Convention on Civil Liability for Oil Pollution Damage (CLC 69). This instrument has paramount implications for the insurance industry. To start with, it prescribes the obligation for all ships flying the flag of a State Party and carrying 2000 GRT of persistent oil or above to insure their liability for the limits established in the convention. The most important novelty however is that the convention establishes these limits bearing in mind not any real or notional value of the hull and freight, but the insurance capacity available to the shipowner at a reasonable price. In this way the risk of pollution damage from ships is transferred to the insurance market for the purpose of enabling fair compensation. The shipowner's risk against third parties becomes essentially an insurable risk, the limits of which are not related to the value of the hull or the cargo but to the amount of compensation made available by the insurer (normally Protection and Indemnity Clubs). 
6.7. CLC provides for strict liability (subject to few exceptions) on the shipowner. The limits are calculated in gold francs or francs Poincaré. A Protocol adopted in 1976 which amends the original convention, adopts the Special Drawing Right (SDR), as defined by the International Monetary Fund as the Unit of Account instead of the gold franc. At present, the shipowner is entitled to limit his liability to an amount of 133 SDR (approx. US $\$ 181$ ) per ton of the ship's tonnage or 14 million SDR (US $\$ 19,3$ million) whichever the less). CLC has been adopted by 67 States.

6.8. CLC 69 only camc into being as a result of a compromise reached at the Conference when a new instrument was proposed, providing for the contribution by the crude oil receivers to the payment of adequate compensation for oil pollution damage. As main beneficiaries of the transport by sea of such a polluting merchandise, it was insisted, they should play their part in such compensation. The contribution of the cargo owners was regulated in the International Convention on the Establishment of an International Fund for Compensation for Oil Pollution Damage (Fund Convention). This Convention provides for supplementary compensation to those who cannot obtain full and adequate compensation for oil pollution damage under CLC. Such compensation is paid by the Intcrnational Oil Pollution Compensation Fund (IOPC Fund) which is financed by persons who receive crude oil and heavy fuel oil after a sea transport in a State Party to the Fund Convention. Only those States which become Parties to CLC can be also Parties to the Fund Convention. The compensation payable by the IOPC Fund in respect of an incident is limited to an aggregate amount of 60 million SRD (approx. US $\$ 81.8$ million) including the sum actually paid by the owner under CLC. The Fund pays compensation directly to the victims of oil pollution damage and has established a reputation for its quick settlement of claims.

6.9. It would be beyond the scope of this paper to refer to all the features of the CLC and the Fund Convention. Both instruments are strongly interrelated as part of an international legal regime designed to provide compensation for oil pollution damage from ships. This regime was featured as an adequate alternative to two extreme positions, namely the one advocating the direct State responsibility in respect of the compensation to be paid for oil pollution damage, and the opinion according to which States should absolutely abstain from intervening in the management of oil pollution risks through the imposition of a compulsory insurance cover and the establishment of liability limits on the basis of available insurance capacity. These positions repeatedly clashed during the proceedings leading to the adoption of UNCLOS. The compromise adopted in this last convention acknowledges that there is a State obligation in ensuring adcquatc compensation pollution damage to the marine environment. This obligation is however conceived as an indircct one: it does not necessarily compel the State to assume direct responsibility for such damagc but imposes upon Governments the obligation to ensure that an adequate lcgal regime is cnforced to provide for adequate compensation. Article 235 of UNCLOS is no doubt an important acknowledgement of the role to play by the insurance industry in the compensation of pollution damage to the marine environment:

\section{Article 235 - Responsibility and liability}

1 States are responsible for the fulfilment of their international obligations concerning the protection and preservation of the marine environment. They shall be liable in accordance with international law.

2 States shall ensure that rccourse is available in accordance with their legal systems for prompt and adequate compensation or other relicf in respect of damage caused by 
pollution of the marine environment by natural or juridical persons under their jurisdiction.

3 With the objective of assuring prompt and adequate compensation in respect of all damage caused by pollution of the marine environment, States shall co-operate in the implementation of existing international law and the further development of international law relating to responsibility and liability for the assessment of and compensation for damage and the settlement of related disputes, as well as, where appropriate, development of criteria and procedures for payment of adequate compensation, such as compulsory insurance or compensation funds."

6.10. The limits of compensation payable under CLC and the Fund Convention have been increased by the 1984 protocols to each of them, which are not yet in force. The 1984 CLC protocol increases these limits in a scale according to tonnage up to approximately US $\$ 78$ million. The aggregate amount in accordance with the 1984 Protocol to the Fund convention is of a maximum of US $\$ 177$ million and, in exceptional circumstances can be increased up to US $\$ 261$ million.

6.11. Reference has already been made to the TOVALOP and CRISTAL schemes which were established in 1969 and 1971 respectively, for the purpose of providing benefits comparable to those available under CLC and the Fund Convention in States which have not ratified these instruments. Both TOVALOP and CRISTAL were considered interim solutions and as such, likely to remain in operation only until the international conventions had worldwide application. From being alternatives to the conventions, it seems that these schemes are now complementary to them: not only do they apply in non CLC and Fund countries, but also in respect of these countries which have adopted both conventions. Some precisions are necessary to avoid confusion in the extremely complex subject of the relationship of these two industry schemes with CLC and the Fund Convention:

- while the conventions provide for a legal régime (i.e. mandatory in respect of the countries which have ratified the conventions), TOVALOP and CRISTAL are voluntary schemes;

- TOVALOP and CRISTAL have scopes of application which are very similar to those of the CLC and Fund Convention. However, the voluntary schemes cover certain risks not presently covered by the international conventions. For instance, TOVALOP and CRISTAL cover "pure threat situations", i. e. preventive measures taken if no oil is actually spilled. In addition, TOVALOP applies to spills from tankers in ballast. This additional cover adequately complements the mandatory one offered by CLC;

- there is a reimbursement system for members of CRISTAL who pay contributions for the IOPC Fund because they are situated in a State Party to the Fund Convention. These CRISTAI, members will be reimbursed by CRISTAL for contributions paid to the IOPC Fund in respect of incidents involving cargoes owned by any CRISTAL member. A corresponding provision in the new TOVALOP provides that tanker owners will contribute to this reimbursement up to the applicable TOVALOP limit.

6.12. IMO pursued its work on the elaboration of liability convention limits for maritime accidents with the adoption of the 1974 Athens Convention which establishes liability limits in respect of death and injuries suffered by passengers and damage to their equipment.

6.13. In 1976, an international conference was held in London under the auspices of IMO which adopted the International Convention on Limitation of Liability for Maritime Claims 
(LLMC 1976). In this case, the assessment of liability limits on the basis of the available insurance capacity applies in respect of maritime claims in gencral (i.c. claims other than those originated in oil pollution damage). At the time of the Convention the cvidence submitted by the International Union of Marinc Insurers (IUMI) held that the maximum available capacity for the shipowner's liability insurance provided by the Protection and Indemnity ( $\mathrm{P}$ and I Clubs) was over 100 million dollars for each accident to each vessel. Following the production of this evidence and the discussions on the cost of the shipowner's liability insurance, the Convention established limits of liability calculated on the basis of the Special Drawing Right (SDR) as defined by the International Monctary Fund as the Unit of Account. The limits vary in accordance with the kind of claims (life and personal injuries and property claims in general) and the tonnage of the ship. It is important to note that, unlike the casc of CLC, LLMC docs not impose upon the shipowner the obligation to contract compulsory insurance to cover for damage up to the limits established by the convention. In this casc, it was felt that the contracting of an insurance cover could not be regulated at an international level, in view of the technical difficulties involved in assessment of a variety of risks. There were also legal difficulties: not every country was ready to accept that all third party liability for maritime claims should be related, in all cases, to a system of compulsory insurance.

6.14. The Legal Committee of IMO is at present engaged in the elaboration of a new treaty instrument which would create another special régime of compensation. this time in respect of damage caused by noxious and hazardous substances other than oil transport by sea. It seems that the polluting potential of some of these substances is such that if they are spilled into the sea, even in small quantities, they would cause devastating damage. In this case the possibility of imposing upon the shipowner the obligation of contracting a third party liability cover present some additional difficulties: unlike the case of oil pollution, the variety of hazardous and noxious substances transported by sea complicates the assessment of risks for the purposes of regulating a compulsory insurance at an intcrnational level; therc is some uniformity when damage to be covered is caused by the spill of one single commodity, as is the case of oil. On the contrary, risk assessment is complicated in the case of hazardous and noxious substances which can damage the marine environment in a different way, depending on their kind, quantity and their different damage potential when mixed with other substances.

\section{Epilogue}

7.1. As long as technological innovations result in more complex risks of a catastrophic effect, it seems likely that Govcrnments will keep on prcssing for the adoption of international instruments regulating risk management in a mandatory way. Equally, new instruments will seek to ensure that adequate compensation is provided to victims of maritime accidents, whether or not they involve pollution damage.

7.2. Howcver, the efforts of governments, international organizations, insurcrs and classification societies can only be successful if the pace of technology is effectively matched by the development of skills and resources nceded to provide adequate risk management. Otherwise, progress becomes a source of damage which no international convention can control or neutralize. 


\section{Status of conventions and other multilateral treaty instruments for which the Organization or its Secretary-General perform depositary or other functions}

International Convention for the Safety of Life at Sea, 1974. as amended.

Protocol of 1978 relating to the International Convention for the Safety of Life at Sea, 1974, as amended.

Protocol of 1988 relating to the International Convention for the Safety of Life at Sea, 1974.

Convention on the International Regulations for Preventing Collisions at Sea, 1972, as amended.

International Convention for the Prevention of Pollution from Ships, 1973, as modified by the Protocol of 1978 relating thereto.

Convention on Facilitation of International Maritime Traffic, 1965, as amended.

International Convention of Load Lines, 1966.

Protocol of 1988 relating to the International Convention on Load Lines, 1966.

International Convention on Tonnage Measurement of Ships, 1969.

International Convention relating to Intervention on the High Seas

in Cases of Oil Pollution Casualties, 1969.

Protocol relating to Intervention on the High Seas in Cases of Pollution by Substances other than Oil, 1973.

International Convention of Civil Liability for Oil Pollution Damage, 1969.

Protocol (of 1976) to the International Convention on Civil Liability for Oil Pollution Damage, 1969.

Protocol of 1984 to amend the International Convention on Civil Liability for Oil Pollution Damage, 1969.

Special Trade Passenger Ships Agreement, 1971.

Protocol on Space Requirements for Special Trade Passenger Ships, 1973.

Convention relating to Civil Liability in the Field of Maritime Carriage of Nuclear Material, 1971.

Intcrnational Convention on the Establishment of an International Fund for Compensation for Oil Pollution Damage, 1971.

Protocol (of 1976) to the International Convention on the Establishment of an International Fund for Compensation for Oil Pollution Damage, 1971.

Protocol of 1984 to amend the International Convention on the Establishment of an International Fund for Compensation for Oil Pollution Damage, 1971.

International Convention for Safe Containers, 1972, as amended.

Athens Convention relating to the Carriage of Passengers and their Luggage by Sea, 1974.

Protocol to the Athens Convention relating to the Carriage of Passengers and their Luggage by Sea, 1974. 
Protocol of 1990 to amend the Athens Convention relating to the Carriage of Passengers and their Luggage by Sea, 1974.

Convention on the International Maritime Satcllite Organization (INMARSAT), as amended.

Operating Agreement (signatory) (INMARSAT).

Convention of Limitation of Liability for Maritime Claims, 1976.

Torremolinos International Convention for the Safety of Fishing Vessels, 1977.

International Convention on Standards of Training,

Certification and Watchkeeping for Seafarers, 1978.

International Convention on Maritime Search and Rescuc, 1979.

Convention for the Suppression of Unlawful Acts against the Safety of Maritime Navigation, 1988.

Protocol for the Suppression of Unlawful Acts against the Safety of Fixed Platforms Located on the Continental Shelf, 1988.

International Convention on Salvage, 1989.

International Convention on Oil Pollution

Preparedness, Response and Co-operation, 1990.

Convention on the Prevention of Marine Pollution by Dumping of Wastes and Other Matter, 1972, as amended.

International COSPAS-SARSAT Programme Agreement. 